Check for updates

Cite this: RSC Adv., 2018, 8, 12701

Received 9th January 2018

Accepted 20th March 2018

DOI: $10.1039 / \mathrm{c} 8 \mathrm{ra00226f}$

rsc.li/rsc-advances

\section{Fluorinated graphene/sulfur hybrid cathode for high energy and high power density lithium primary batteries $\uparrow$}

\author{
Sikan Peng, (D) Shaojiu Yan, ${ }^{*}$ Nan Wang, Wenzheng Nan, Jixian Wang, Xiang Chen, \\ Chen Wang, Xin Qi and Shenglong Dai
}

It is a great challenge to obtain high performance carbon fluoride $\left(\mathrm{CF}_{x}\right)$ cathodes with high specific capacity and good rate performance due to the electronic conductivity of $\mathrm{CF}_{x}$ being known to decrease with an increase in the specific capacity. Herein, we propose a novel fluorinated graphene (FG)/sulfur hybrid cathode to enhance both the energy density and power density of lithium/carbon fluoride (Li/CF $F_{x}$ batteries. Impressive enhancements of the specific capacity, discharge voltage, and rate capability are demonstrated with the novel FG/sulfur hybrid cathode. In comparison with the pristine FG cathode, the hybrid cathode exhibits higher electrochemical activity, lower overpotential, and faster ion transfer over the main discharge range. Furthermore, when the melt-diffusion method is used to prepare the hybrid cathode, the uncommon monoclinic sulfur is presented under ambient temperature. A significant synergistic effect which reduces the reaction resistance effectively is demonstrated with the presence of monoclinic sulfur, leading to the highest energy density of $2341 \mathrm{~W} \mathrm{~h} \mathrm{~kg}^{-1}$ and a power density up to $13621 \mathrm{~W} \mathrm{~kg}^{-1}$ at $8.0 \mathrm{~A} \mathrm{~g}^{-1}$. Our results are expected to introduce a new generation of high energy and high power density lithium primary cells, based on a simple and effective strategy employing FG/S hybrid cathodes.

\section{Introduction}

Lithium/carbon fluoride $\left(\mathrm{Li} / \mathrm{CF}_{x}\right)$ batteries are known to have the highest theoretical specific energy density (about $2180 \mathrm{~W} \mathrm{~h} \mathrm{~kg}^{-1}$ ) among all commercially available solid cathode primary lithium batteries. ${ }^{1-3}$ The carbon fluoride $\left(\mathrm{CF}_{x} ; 0<x<\right.$ 1.3) cathode has many unique advantages, such as a high theoretical potential, a wide operational temperature range, and a flat discharge potential. ${ }^{4,5} \mathrm{The} \mathrm{CF}_{x}(x=1)$ cathode has an open circuit potential of $3.0-3.5 \mathrm{~V} v s$. $\mathrm{Li}^{+} / \mathrm{Li}$ in most non-aqueous liquid electrolytes. ${ }^{6}$ However, the operating discharge potential is about $2.5 \mathrm{~V} v s . \mathrm{Li}^{+} / \mathrm{Li}$, showing significant polarization due to the low electronic conductivity of $\mathrm{CF}_{x}$ materials and high activation energy of the cathodic reaction. Moreover, the specific capacity of $\mathrm{CF}_{x}$ is dependent on the fluorine content, while the electronic conductivity of $\mathrm{CF}_{x}$ is known to decrease with increasing fluorine content. ${ }^{7,8}$ These intrinsic drawbacks of $\mathrm{CF}_{x}$ also lead to a poor high-rate performance, together with an initial voltage delay at the beginning of discharge when used as a cathode in $\mathrm{Li} / \mathrm{CF}_{x}$ batteries. Although the commercialization of $\mathrm{Li} / \mathrm{CF}_{x}$ batteries began earlier than other solid series

Beijing Institute of Aeronautical Materials (BIAM), Beijing, 100095, P. R. China. E-mail: shaojiuyan@126.com

$\dagger$ Electronic supplementary information (ESI) available. See DOI: $10.1039 / \mathrm{c} 8 \mathrm{ra00226f}$ batteries, the current applications are mainly limited to the lowto-medium power devices, such as electronic backups and medical implants. ${ }^{4}$

In order to enhance the discharge performance of $\mathrm{Li} / \mathrm{CF}_{x}$ batteries, several approaches have been attempted, all focusing on improving the rate capability. For example, sub-fluorinated ${ }^{9,10}$ or conductive material-coated ${ }^{11-13} \mathrm{CF}_{x}$ were shown to facilitate electron transport. In addition, composite cathodes were prepared with a second material that has good rate capability or a slightly higher discharge voltage than $\mathrm{CF}_{x}$, such as $\mathrm{MnO}_{2},{ }^{4,14} \mathrm{LiV}_{3} \mathrm{O}_{8},{ }^{15}$ and $\mathrm{Ag}_{2} \mathrm{~V}_{4} \mathrm{O}_{11}{ }^{16-18}$ Since the second cathode material discharged first, the initial voltage delay region of the $\mathrm{CF}_{x}$ could be eliminated and the rate performance improved to some extent. However, these improvements occurred at the expense of energy density due to a decrease in the mass specific capacity of the active cathode material. As opposed to sacrificing the battery capacity while enhancing the rate performance, a simple strategy is proposed here in consideration that the increase in specific capacity of active material can also improve the cell performance under high discharge current density based on the unit mass of active material. The sulfur which has high theoretical specific capacity would be a suitable candidate for preparing high performance hybrid cathode.

Although Li/S batteries are usually considered as secondary batteries, the great potential for using sulfur as cathodic material in primary batteries has been recently realized. ${ }^{2}$ In the 
present work, the combination of $\mathrm{CF}_{x}$ and sulfur is proposed to form a hybrid cathode in order to take advantage of the extremely high specific energy density of sulfur $\left(2600 \mathrm{~W} \mathrm{~h} \mathrm{~kg}^{-1}\right)$. In this way, the specific capacity of the hybrid cathode material is expected to exceed the limitation caused by the fluorine content in $\mathrm{CF}_{x}$, allowing the energy and power density to increase. Moreover, as sulfur has a lower discharge plateau (about 2.1-2.3 V vs. $\left.\mathrm{Li}^{+} / \mathrm{Li}\right)^{\mathbf{1 9}, 20}$ than that of $\mathrm{CF}_{x}$, the reaction products from $\mathrm{CF}_{x}$ would provide a good conductive network to effectively use the beneficial properties of sulfur. Thus, fluorinated graphene (FG) with a unique morphology and properties was chosen to fabricate a novel hybrid cathode with sublimed sulfur.

In this study, FG/S hybrid cathodes for $\mathrm{Li} / \mathrm{CF}_{x}$ batteries are explored for the first time to the best of our knowledge. The sulfur has been successfully incorporated with FG through a facile process. The unique electrochemical behavior of the FG/ $S$ hybrid cathodes and their impact on the discharge performance of $\mathrm{Li} / \mathrm{CF}_{x}$ batteries are systematically evaluated and discussed. The capacity and rate performance of FG/S hybrid cathode are much better compared with that of pristine FG cathode. Especially, with the presence of monoclinic sulfur, a synergistic effect and effective charge transfer in the novel hybrid system have been demonstrated. These results may open a new avenue to improve the energy and power performance of $\mathrm{Li} / \mathrm{CF}_{x}$ batteries.

\section{Experimental}

Fluorinated graphene $(\mathrm{F} / \mathrm{C}=0.90)$ obtained from Zhongshan Photoelectric Material Co., Ltd. was used as received. Sublimed sulfur was ground manually for half an hour in an agate mortar. Two types of FG/S hybrid materials were prepared for comparison. In the first type of hybrid cathode (FG/S-1), a mixture of FG and sublimed sulfur was prepared mechanically using a vortex oscillator (DragonLab MX-S, China). For the second type (FG/S2 ), the melt-diffusion method was used to incorporate the sublimed sulfur into the $\mathrm{FG}$ at $155^{\circ} \mathrm{C}$ for $12 \mathrm{~h}$ in an argon-filled vessel. For both samples, the sulfur content was $30 \mathrm{wt} \%$.

Fourier transform infrared (FTIR) spectroscopy (Spectrum 400 , USA) was used to identify the chemical structure of the cathode materials. Powder X-ray diffraction (XRD) patterns were recorded using a diffractometer (Bruker D8 Advance, Germany) using copper $\mathrm{K} \alpha$ radiation $(40 \mathrm{kV}, 40 \mathrm{~mA}, \lambda=1.5406 \AA$ ) over a 2 theta range of $10^{\circ}$ to $80^{\circ}$. The microstructure of the samples was characterized using a high resolution field-emission transmission electron microscope (TEM, FEI Tecnai G2 F30, USA) and an scanning electron microscopy (SEM, FEI Nova NanoSEM 450, USA), where the latter was equipped with an energy dispersive X-ray spectroscopy (EDS) system used for producing elemental maps. The chemical structure and the chemical environment of $\mathrm{S}$ at the surface of FG/S-2 were studied by X-ray photoelectron spectroscopy (XPS, Thermo escalab 250Xi, USA). A Shirley-type background was removed from the spectra before de-convolution.

The cathodes were prepared by casting a uniform slurry of the active material (FG, FG/S-1, or FG/S-2), polyvinylidene difluoride, and HS-100 (Denka, Japan) in a weight ratio of $80: 10: 10$ in $N$-methyl-2-pyrrolidinone solvent onto the aluminum foil via the doctor blade casting method. The electrode was then punched into round discs with a diameter of $14 \mathrm{~mm}$ after drying thoroughly at $60{ }^{\circ} \mathrm{C}$ for $24 \mathrm{~h}$ in a vacuum oven. The prepared discs were then transferred into an argonfilled glove box to undertake cell assembly. 2016-type button cells were assembled with lithium foil as the anode, Celgard ${ }^{\circledR}$ 2325 membrane as the separator, and $1.0 \mathrm{~mol} \mathrm{~L}^{-1}$ LiTFSI in DME/DOL (1 : $1 \mathrm{v} / \mathrm{v}$, with $\left.1.0 \mathrm{wt} \% \mathrm{LiNO}_{3}\right)$ as the electrolyte.

The button cells were discharged under different current densities from 0.05 to $8.0 \mathrm{~A} \mathrm{~g}^{-1}$ (calculated using the mass of the active material in the cathode) applying a Land CT2001A battery test station (LANHE, China) with a terminal voltage of $1.5 \mathrm{~V}$. Cyclic voltammetry (CV) measurements were conducted using a CHI1000C instrument (Chenhua, China) from 3.0 V to $1.5 \mathrm{~V} v s$. $\mathrm{Li}^{+} / \mathrm{Li}$ at a scanning rate of $0.05 \mathrm{mV} \mathrm{s}^{-1}$. The galvanostatic intermittent titration technique (GITT) was employed at $0.05 \mathrm{~A} \mathrm{~g}^{-1}$ for $20 \mathrm{~min}$ with an interruption of $4 \mathrm{~h}$ between each pulse. Electrochemical impedance spectroscopy (EIS) measurements were performed using an electrochemical workstation (Zahner-Zennium, Germany) under the open circuit voltage over a frequency range between $1 \mathrm{MHz}$ and 10 $\mathrm{mHz}$. The amplitude of the AC voltage was $5 \mathrm{mV}$. Impedance responses for testing hybrid cathodes were fitted by using Zview program.

\section{Results and discussion}

The chemical structures of the FG and the as-prepared hybrid materials were examined by analyzing their FTIR spectra (Fig. S1 $\dagger$ ). Both samples showed a peak at $1203 \mathrm{~cm}^{-1}$, which was ascribed to the stretching vibration of covalent $\mathrm{C}-\mathrm{F}$ bonds. In addition, the shoulder at $1328 \mathrm{~cm}^{-1}$ was assigned to the covalent $\mathrm{C}-\mathrm{F}_{2}$ bonds. Moreover, no peaks were present around $1143 \mathrm{~cm}^{-1}$ or $1112 \mathrm{~cm}^{-1}$ indicating that there were no semiionic $\mathrm{C}-\mathrm{F}$ bonds. ${ }^{5,21,22}$ Compared with the pristine $\mathrm{FG}$, the hybrid materials (FG/S-1 and FG/S-2) showed no new peaks, which confirmed that the structure of FG did not change after the incorporation of sulfur. The XRD patterns (Fig. 1a) showed that the hybrid materials had main reflections which could be indexed to the structure of pristine FG, confirming again that sulfur incorporation did not change the structure of the FG. The peaks around $12.5^{\circ}$ and $41^{\circ}$ were indexed to the (001) and (100)

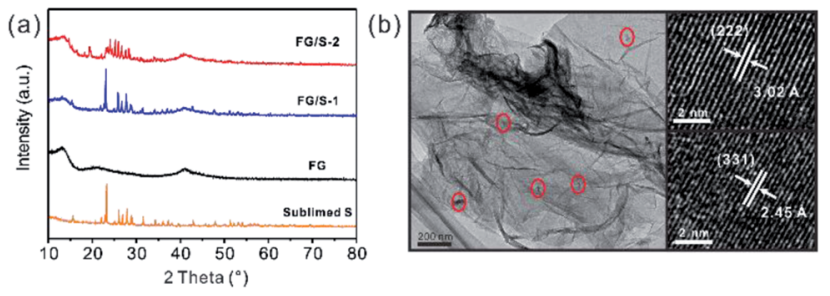

Fig. 1 (a) XRD patterns of sublimed sulfur, FG, FG/S-1, and FG/S-2. (b) TEM image of the FG/S-2 and representative HRTEM images taken from the marked sulfur particles in red circles. 
reflections of FG, respectively. The (001) reflection is characteristic of compounds with very high fluorine levels. ${ }^{5,23}$ The peak at $41^{\circ}$ is associated with the $\mathrm{C}-\mathrm{C}$ in-plane length., ${ }^{5,22}$ However, the (002) reflection at around $26.5^{\circ}$ almost disappeared probably due to the high level of fluorination and the crinkled structure with poor regularity along the stacking direction. ${ }^{22,23}$ In addition, the typical pattern of an orthorhombic type of sulfur (PDS N08-0247) was present in the sublimed S and FG/S1. However, FG/S-2 showed a pattern from an unexpected monoclinic type of sulfur (PDS N34-0941), suggesting a phase transition during the melt-diffusion process. Monoclinic type of sulfur is unusual because it is normally stable above $95{ }^{\circ} \mathrm{C},{ }^{24}$ below this orthorhombic type of sulfur is the more stable allotrope. Monoclinic sulfur will turn slowly into the more stable orthorhombic form on standing below $95{ }^{\circ} \mathrm{C}$. Nevertheless, in FG/S-2, the monoclinic sulfur kept stable at ambient temperature rather than the typical orthorhombic phase, similar to the result previously reported by Moon et al. ${ }^{25}$ It supposed that during the heat treatment of $\mathrm{FG} / \mathrm{S}-2$ the orthorhombic sulfur firstly became monoclinic sulfur above $95{ }^{\circ} \mathrm{C}$, then became liquid sulfur above $119{ }^{\circ} \mathrm{C}$ which then well diffused into the porous structure of FG. When it allowed to cool, the liquid sulfur crystallized slowly as monoclinic sulfur, where the carbon wall of FG may play a role in the formation of the monoclinic phase..$^{25}$ As a result, the crystallized monoclinic sulfur was confined in the porous structure of FG (Fig. 1b) and retained its stability even at room temperature, after a heat treatment within a confined environment in nanometer dimensions. In another hand, Jung et al. ${ }^{26}$ recently predicted that if carbon atoms penetrate the sulfur at elevated temperatures, the monoclinic phase could become more stable than the orthorhombic one. More importantly, it is believed that the monoclinic phase can promote a faster ion transport compared to the orthorhombic phase ${ }^{26}$ which is crucial for better cell performance during discharging.

To analyze the nature of chemical bonds in FG and investigate the interaction between S and FG, XPS spectra of C 1s, F 1s, and $\mathrm{S} 2 \mathrm{p}$ for pristine $\mathrm{FG}$ and hybrid FG/S-2 materials were measured and are illustrated in Fig. 2. As shown in Fig. 2a and c, the $\mathrm{C}$ 1s spectra are deconvoluted to several symmetrical peaks. Two peaks at $284.8 \mathrm{eV}$ and $285.9 \mathrm{eV}$ are ascribed to $\mathrm{sp}^{2} \mathrm{C}=\mathrm{C}$ bonds and $\mathrm{sp}^{3} \mathrm{C}-\mathrm{C}$ bonds. ${ }^{1,5,22}$ Besides, there are two peaks at $290.1 \mathrm{eV}$ and $291.7 \mathrm{eV}$ assigned to $\mathrm{C}-\mathrm{F}$ and $\mathrm{C}-\mathrm{F}_{2}$ bonds, respectively. ${ }^{1,5,22}$ Interestingly, $\mathrm{FG} / \mathrm{S}-2$ displays a new peak at about $287.4 \mathrm{eV}$ which is associated with $\mathrm{C}=\mathrm{S}$ bonds. ${ }^{27,28} \mathrm{Though}$ there are some fluctuations due to the low content of sulfur, the interaction between FG and S can also depicted by the S 2p spectrum of FG/S-2, as shown in Fig. 2e. The spectrum of sulfur were carefully deconvoluted into four component peaks. The peak at $165.2 \mathrm{eV}$ corresponds to $2 \mathrm{p}_{1 / 2}$ spin-orbital coupling of $2 \mathrm{p}$ electrons and other three components $\left(2 \mathrm{p}_{3 / 2}-\mathrm{I}, 2 \mathrm{p}_{3 / 2}-\mathrm{II}\right.$ and $2 \mathrm{p}_{3 /}$ ${ }_{2}$-III) values at $164.5,164.0$, and $163.5 \mathrm{eV}$ correspond to the presence of $\mathrm{C}=\mathrm{S}, 2 \mathrm{p}_{3 / 2}$ spin-orbital coupling and $\mathrm{C}-\mathrm{S}$ bond, respectively. ${ }^{29-32}$ From the F 1s XPS spectra in Fig. $2 \mathrm{~b}$ and d, the characteristic peaks are found at $688.8 \mathrm{eV}$ corresponding to the covalent $\mathrm{C}-\mathrm{F}$ bonds. There is no significant difference in the $\mathrm{F}$ 1s spectra between FG and FG/S-2, which confirmed that there
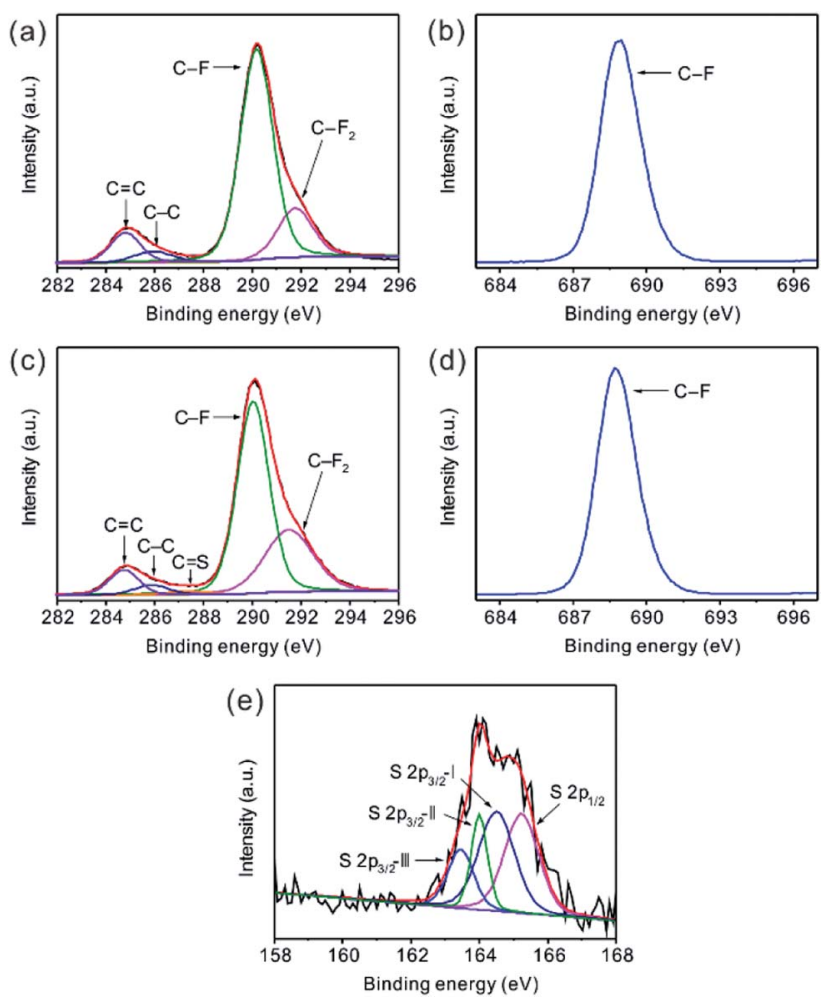

Fig. 2 High-resolution XPS spectra of ( $a$ and c) C 1s, (b and d) F $1 \mathrm{~s}$ and (e) $S 2 p$ of ( $a$ and b) FG and (c-e) FG/S-2.

were no semi-ionic C-F bonds ${ }^{5,21,22}$ presented after the meltdiffusion treatment. Hence, the XPS results together with the XRD results above, support the observation that some of the sulfur atoms are chemically bonded to the FG after heat treatment in FG/S-2. These chemical interactions and carbon penetration into sulfur could help the monoclinic phase retaining its stability under room temperature. It would also benefit the charge transfer between FG and sulfur during cell discharging.

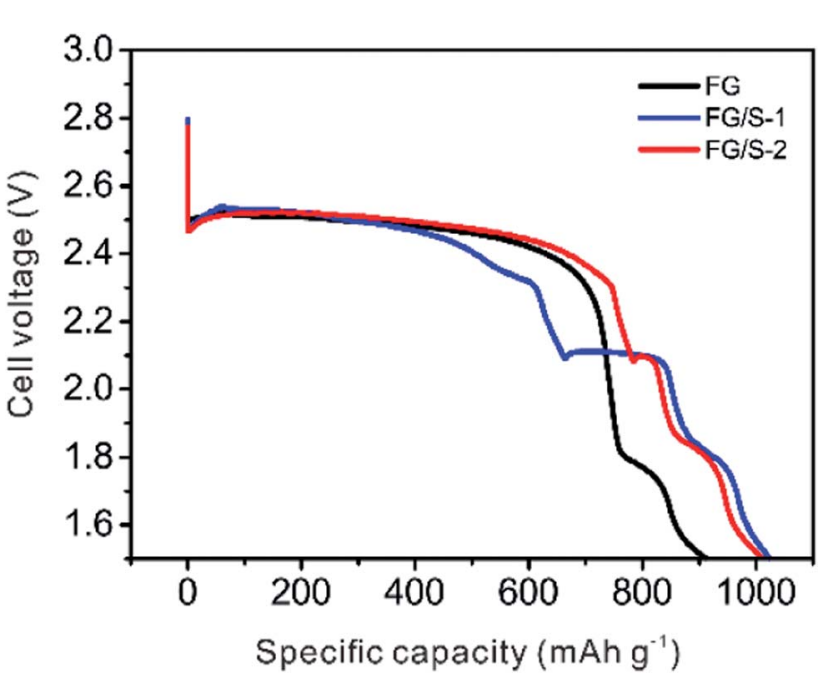

Fig. 3 Typical discharge profiles of FG and hybrid cathodes. The discharge current density in this graph was kept at $0.05 \mathrm{~A} \mathrm{~g}^{-1}$. 
The discharge profiles of different cathodes are presented in Fig. 3. The pristine FG had a discharge plateau located at about $2.5 \mathrm{~V}$, and it delivered $913 \mathrm{~mA} \mathrm{~h} \mathrm{~g}^{-1}$ at $0.05 \mathrm{~A} \mathrm{~g}^{-1}$ which was above the theoretical value ( $\left.829 \mathrm{~mA} \mathrm{~h} \mathrm{~g}^{-1}, \mathrm{~F} / \mathrm{C}=0.90\right)$. The extra capacity could be attributed to the decomposition of $\mathrm{LiNO}_{3}$ and side reactions of diverse intermediates with electrolyte components. ${ }^{33}$ These side reactions were taking place below about $1.85 \mathrm{~V}$ which was observed for all three samples. The FG/S-1 sample showed an open circuit voltage of $2.79 \mathrm{~V}$, higher than that of pristine FG $(2.63 \mathrm{~V})$. Meanwhile, this sample showed interesting discharge behavior that demonstrated the feasibility of a FG/S hybrid cathode. At first, there was a plateau around $2.5 \mathrm{~V}$, attributed to the reduction of FG, and an initial voltage delay was observed. Then the reduction of sulfur from $\mathrm{Li}_{2} \mathrm{~S}_{8}$ to $\mathrm{Li}_{2} \mathrm{~S}_{n}(n=4-8)$ shows a clear discharge region between $2.4 \mathrm{~V}$ and $2.1 \mathrm{~V}$. After that, a plateau at $2.1 \mathrm{~V}$ was presented, which corresponded to the further reduction reaction to $\mathrm{Li}_{2} \mathrm{~S} / \mathrm{Li}_{2} \mathrm{~S}_{2}$. This discharge profile for FG/S-1 seemed like a combination of the two typical discharge curves of $\mathrm{Li} / \mathrm{CF}_{x}$ and $\mathrm{Li} / \mathrm{S}$ batteries (Fig. S2 $\dagger$ ). Both FG and S could exhibit their discharge characteristics perfectly. In addition, the order of discharge was first the FG, then both FG and S, and finally the S. In this case, the transitional discharge region could be around $2.5 \mathrm{~V}$ to $2.4 \mathrm{~V}$ for the simultaneous discharge of FG and S. Moreover, a specific capacity of $1024 \mathrm{~mA} \mathrm{~h} \mathrm{~g}{ }^{-1}$ associated with an energy density of $2319 \mathrm{~W} \mathrm{~h} \mathrm{~kg}^{-1}$ was achieved by the FG/S-1 sample. This result verified that incorporating sulfur into FG increased the specific capacity and energy density of the cathode compared with the pristine FG cathode, as expected.

In contrast, FG/S-2 exhibited a similar but distinctive discharge profile compared with FG/S-1. The one main difference was that the transitional discharge region of the FG/S-2 between $2.5 \mathrm{~V}$ to $2.4 \mathrm{~V}$ was extended. As a result, the first sulfur reduction region shifted along the $x$-axis to a higher specific capacity and the plateau width at $2.1 \mathrm{~V}$ shortened. Nevertheless, FG/S-2 delivered a comparable specific capacity of $1011 \mathrm{~mA} \mathrm{~h} \mathrm{~g}^{-1}$ along with over $70 \%$ specific capacity output above $2.3 \mathrm{~V}$, resulting in a higher energy density of $2341 \mathrm{~W} \mathrm{~h} \mathrm{~kg}{ }^{-1}$ than that of FG/S-1. Therefore, the hybrid cathode with monoclinic sulfur is preferable for the application considering the energy output. It has been demonstrated the existence of lithium ions migration from $\mathrm{Ag}_{2} \mathrm{~V}_{4} \mathrm{O}_{11}, \mathrm{LiV}_{3} \mathrm{O}_{8}$ or $\mathrm{MnO}_{2}$ to $\mathrm{CF}_{x}$ in the $\mathrm{CF}_{x} / \mathrm{Ag}_{2} \mathrm{~V}_{4} \mathrm{O}_{11}, \mathrm{CF}_{x} / \mathrm{LiV}_{3} \mathrm{O}_{8}$ or $\mathrm{CF}_{x} / \mathrm{MnO}_{2}$ hybrid cathodes. ${ }^{\mathbf{4 1 5 , 3 4}}$ Hence, a similar charge transfer process would be possible in the case of FG/S-2 hybrid cathode. During the discharge of FG/S-2, lithium ions initially inserted into the FG phase may transfer to the sulfur phase to form $\mathrm{Li}_{2} \mathrm{~S}_{n}(n \leq 8)$, and it was confirmed by the longer plateau width around $2.5 \mathrm{~V}$ than that of FG and FG/S-1. In another hand, the melt-diffusion process benefitted sulfur diffusing into the porous structure of FG during manufacture of FG/S-2, resulting effective physical contact and chemical interaction between monoclinic sulfur and FG for the charge transfer. Therefore, lithium ions transfer successively from FG to sulfur during the discharge process, and hence improving the discharge voltage and energy output of FG/S-2.
To explore the reaction mechanism of hybrid cathodes, CV was performed; the discharge branches of the CV curves for FG, FG/S-1, and FG/S-2 cathodes are presented in the cut-off potential range of 3.0 to $1.5 \mathrm{~V}$ in Fig. $4 \mathrm{a}$. It can be seen that FG had a large reduction peak at $2.26 \mathrm{~V}$ with an onset potential of $2.54 \mathrm{~V}$, which is attributed to the reaction between FG and lithium ions. In addition, a reduction peak below $1.9 \mathrm{~V}$ was observed for all three materials, resulting from the decomposition of $\mathrm{LiNO}_{3}$ and other side reactions with the electrolyte. ${ }^{33}$ We also observed peaks at $2.03 \mathrm{~V}$ and $2.33 \mathrm{~V}$ for sample FG/S-1, where that at $2.03 \mathrm{~V}$ corresponded to the transformation from $\mathrm{Li}_{2} \mathrm{~S}_{4}$ to short-chain polysulfides $\left(\mathrm{Li}_{2} \mathrm{~S} / \mathrm{Li}_{2} \mathrm{~S}_{2}\right) \cdot{ }^{19}$ However, the other peak with an onset at $2.73 \mathrm{~V}$ was attributed to the reduction of either $\mathrm{FG}$ or sulfur, while the reduction peaks overlapped fully. Interestingly, in the case of FG/S-2, a very small peak at $2.15 \mathrm{~V}$ was observed between those at $2.05 \mathrm{~V}$ and $2.32 \mathrm{~V}$. The area of the peak at $2.05 \mathrm{~V}$ decreased significantly compared to that of the FG/S-1 sample, while the area of the peak with an onset at $2.80 \mathrm{~V}$ increased. This change in the peak area is consistent with the difference in plateau width shown in Fig. 3, confirming the existence of charge transfer between FG and sulfur. In addition, the presence of the very small peak at $2.15 \mathrm{~V}$ suggests a probably different reduction route for monoclinic sulfur in the case of FG/S-2. As a result, the FG/S-2 could deliver a long output plateau under high voltage and higher energy density. Moreover, the remarkable increase in onset potential from $2.54 \mathrm{~V}$ for the $\mathrm{FG}$ to above $2.73 \mathrm{~V}$ for the hybrid cathodes indicated improved electrochemical activity and a lower overpotential after hybridization. The dissolved sulfur in electrolyte might play a key role in the promotion of onset potential for hybrid cathodes, since it was known that the discharge voltage of $\mathrm{Li} / \mathrm{CF}_{x}$ cell is related to the solvation process between $\mathrm{Li}^{+}$ion and solvent molecules. ${ }^{6}$

The GITT technique was used to determine the diffusion coefficient of lithium ions $\left(D_{\mathrm{Li}}\right)$ in the different cathodes. ${ }^{35}$ As presented in Fig. $4 \mathrm{~b}$, the $D_{\mathrm{Li}}$ value of FG in this study mainly ranged from $\sim 10^{-13}$ to $\sim 10^{-11} \mathrm{~cm}^{2} \mathrm{~s}^{-1}$, which is about an order of magnitude higher than previously reported, ${ }^{4}$ probably due to the different electrolyte used. The $D_{\mathrm{Li}}$ values of the hybrid cathodes were comparable to that of FG at the beginning of the discharge process as the reaction of FG occurred first. In the potential range from $2.36 \mathrm{~V}$ to $2.15 \mathrm{~V}$ (the sulfur reduction
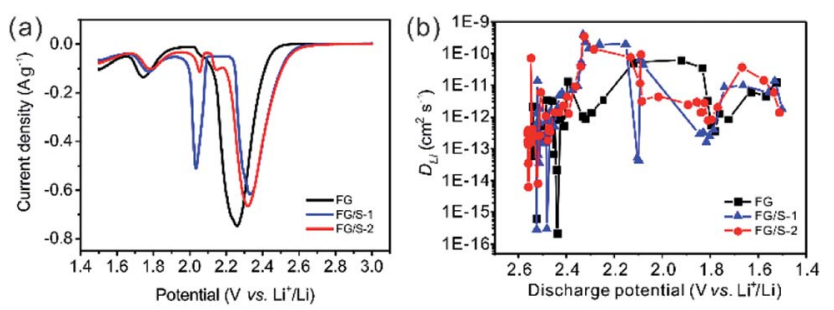

Fig. 4 (a) The cyclic voltammetry profiles of pristine FG, FG/S-1, and $\mathrm{FG} / \mathrm{S}-2$ cathodes at a scanning rate of $0.05 \mathrm{mV} \mathrm{s}^{-1}$. The current density was normalized by the mass of active material in the cathode. (b) The calculated $D_{\mathrm{Li}}$ from the GITT data as a function of the discharge potential during the process. 
region) the $D_{\mathrm{Li}}$ values of the hybrid cathodes were an order of magnitude higher than that of FG. It should be noted that this potential range is one of the main discharge plateaus for hybrid cathodes. In addition, excellent $\mathrm{Li}^{+}$transport properties are crucial for optimized electrochemical performance of a battery. In the range between $2.1 \mathrm{~V}$ and $1.8 \mathrm{~V}$, the $D_{\mathrm{Li}}$ values of the hybrid cathodes were lower than that of pristine FG. This may have resulted from the discharge reaction of the active materials gradually finishing and insoluble $\mathrm{Li}_{2} \mathrm{~S}_{2} / \mathrm{Li}_{2} \mathrm{~S}$ with poor conductivity being deposited. Therefore, incorporating sulfur into the FG could enhance lithium ion diffusion in the main discharge region, and a better rate performance would be possible with the hybrid cathode.

The galvanostatic discharge curves of pristine FG and the hybrid cathodes at different current rates are presented in Fig. 5. Remarkable increases in the discharge voltages and rate performances were achieved in batteries using the hybrid cathodes. However, due to the sluggish kinetics of FG a voltage delay can be seen at the very beginning of the discharge for all cases. The FG cathode showed relatively poor rate capability and specific capacity of $545 \mathrm{~mA} \mathrm{~h} \mathrm{~g}{ }^{-1}$ at $5.0 \mathrm{~A} \mathrm{~g}^{-1}$. In contrast, the FG/S-1 delivered $710 \mathrm{~mA} \mathrm{~h} \mathrm{~g}^{-1}$ at $5.0 \mathrm{~A} \mathrm{~g}^{-1}$, and $570 \mathrm{~mA} \mathrm{~h} \mathrm{~g}^{-1}$ at $6.0 \mathrm{~A} \mathrm{~g}^{-1}$. The FG/S-2 sample exhibited the best rate capability with a specific capacity of $776 \mathrm{~mA} \mathrm{~h} \mathrm{~g}^{-1}$ at $5.0 \mathrm{~A} \mathrm{~g}^{-1}$, an increase of $42 \%$ compared to the FG. It could even work steadily at a fast discharge rate of $8.0 \mathrm{~A} \mathrm{~g}^{-1}$ delivering a specific capacity of $496 \mathrm{~mA} \mathrm{~h} \mathrm{~g}^{-1}$. The median voltages measured at half capacity were plotted (Fig. 5d) for comparing the discharge voltages of different cathodes. It was found that the median voltages of FG/ S-1 were slightly higher than that of FG when the current rate was above $1.0 \mathrm{~A} \mathrm{~g}^{-1}$. However, $\mathrm{FG} / \mathrm{S}-2$ showed a significant enhancement in the median voltage, especially under high current rates, in which an increase of $0.28 \pm 0.035 \mathrm{~V}$ was observed above $1.0 \mathrm{~A} \mathrm{~g}^{-1}$. Interestingly, it was found that in the present novel lithium primary battery system the additive $\mathrm{LiNO}_{3}$ could play a significant role in reducing the initial voltage delay
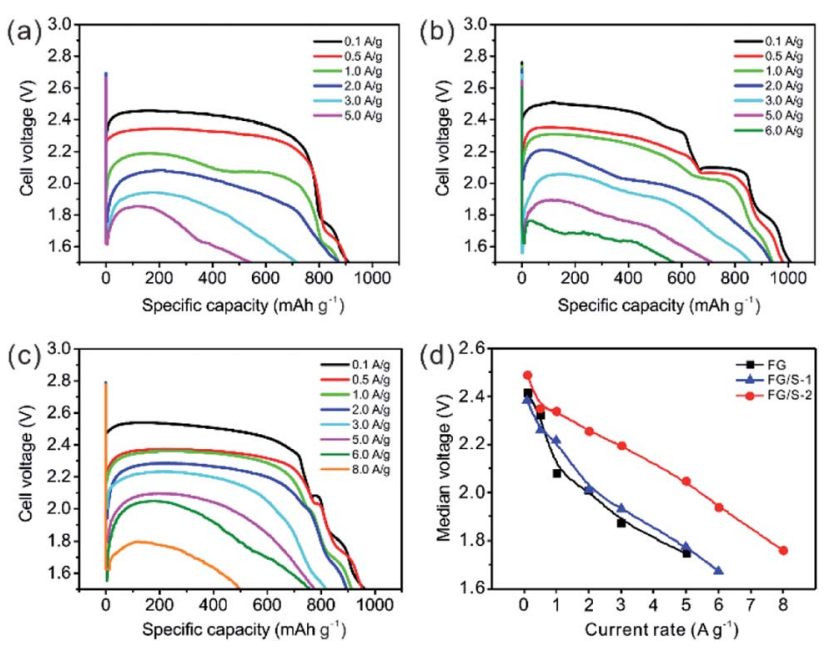

Fig. 5 The galvanostatic discharge curves of (a) FG, (b) FG/S-1, and (c) FG/S-2 at different current rates. (d) The median voltages measured at half capacity. especially at high current rates (as shown in Fig. S4†). The reason can be that the decomposition reaction of $\mathrm{LiNO}_{3}$ would take place below $1.9 \mathrm{~V}\left(v s . \mathrm{Li} / \mathrm{Li}^{+}\right)$, and it had potential anchoring effect in some extent.

The higher rate capability and discharge voltage of FG/S-2 may have been due to the presence of monoclinic sulfur and the effective charge transfer between FG and sulfur. Firstly, monoclinic sulfur has faster ion transport than the orthorhombic phase. ${ }^{26}$ Then it could have better output performance under high discharge current rates. Secondly, the monoclinic sulfur embedded into the porous structure of FG could provide some synergistic effects; for example, efficient $\mathrm{Li}^{+}$diffusion into FG would become possible based on better electrolyte access due to the good distribution of sulfur in the electrode (Fig. S3 $†$ ). Thirdly, there would have a different reaction route that allowed releasing more capacity over the high output plateau due to the effective charge transfer between FG and sulfur as verified by the typical discharge profiles and CV results. These features are important for fulfilling both high energy and high power density cell performances.

The Ragone plot shown in Fig. 6 demonstrates the excellent performance of FG/S-2 in energy and power output compared to pristine FG and FG/S-1, especially at high current rates. Even at low current rates $\left(<1.0 \mathrm{~A} \mathrm{~g}^{-1}\right)$, the delivered energy densities of hybrid cathodes were higher than that of pristine FG, since the incorporated sulfur which has higher specific capacity than that of FG, could offer more output effectively in this hybrid system. The maximum power density of FG/S-2 achieved up to $13621 \mathrm{~W}$ $\mathrm{kg}^{-1}$ at $8.0 \mathrm{~A} \mathrm{~g}^{-1}$. To the best of our knowledge, this is the highest power density reported in the literature, except for the ultra-high output at $24 \mathrm{~A} \mathrm{~g}^{-1}$, as shown in Table 1 . However, we consider that the method developed in the present study is convenient and favorable for commercialization.

The mechanism of rate performance enhancement of FG/S-2 can be further explained by impedance analysis. Fig. 7a shows impedance spectra of FG, FG/S-1, and FG/S-2, which were recorded at $10 \%$ depth of discharge (DOD) state. A suppressed semicircle followed by a sloped straight line at the low frequency end was observed for all samples. FG/S-2 showed the

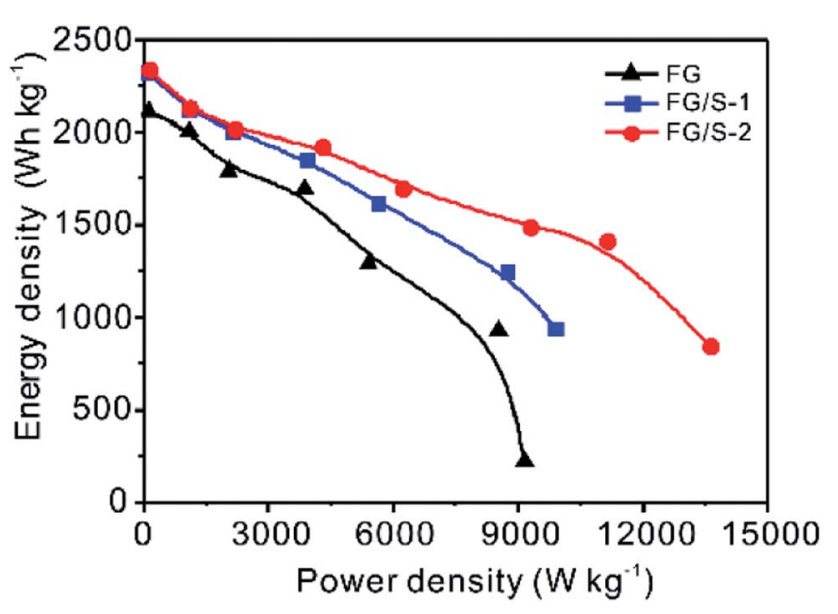

Fig. 6 The Ragone plot of different cathodes. 
Table 1 The comparison of energy and power densities of Li-CF batteries

\begin{tabular}{lllll}
\hline No. & $\begin{array}{l}\text { Active } \\
\text { materials }\end{array}$ & $\begin{array}{l}\text { Power density } \\
\left(\mathrm{W} \mathrm{kg}^{-1}\right)\end{array}$ & $\begin{array}{l}\text { Energy density } \\
\left.(\mathrm{W} \mathrm{h} \mathrm{kg})^{-1}\right)\end{array}$ & References \\
\hline 1 & $\mathrm{CF}_{x} @ \mathrm{C}$ & 3526 & 764 & 11 \\
2 & $\mathrm{CF}_{x} @ \mathrm{PPY}$ & 7091 & & 13 \\
3 & $\mathrm{CF}_{x} / \mathrm{MnO}_{2}$ & 6599 & 1814 & 4 \\
4 & $\mathrm{CF}_{x} / \mathrm{SiO}_{2}$ & 9689 & $\sim 2250$ & 5 \\
5 & $\mathrm{CF}_{x}$ & 44800 & & 1 \\
6 & $\mathrm{CF}_{x} / \mathrm{S}$ & 13621 & 2341 & This study \\
\hline
\end{tabular}

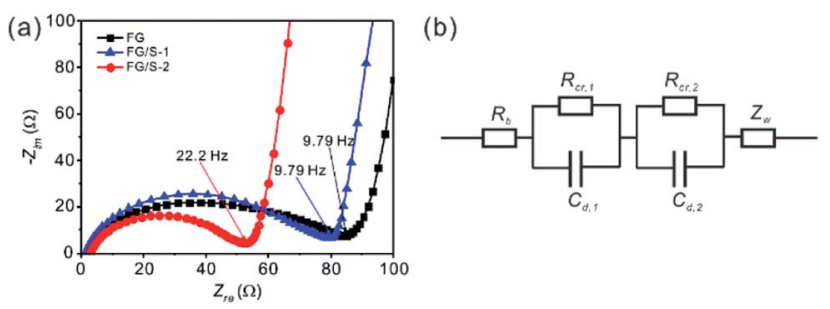

Fig. 7 The electrochemical impedance spectra of (a) FG, FG/S-1, and FG/S-2 cathodes measured at 10\% DOD. (b) Equivalent circuit for analysis of cells with a hybrid cathode.

highest onset frequency between the semicircle and sloped line, indicating faster kinetics. This feature revealed that the FG/S-2 cathode had a higher reaction kinetic with the presence of monoclinic sulfur.

An equivalent circuit was developed to analyze the electrode process of hybrid cathodes (Fig. 7b). As there were two kinds of active materials (FG and $\mathrm{S}$ ) in the cathode, a series circuit was applied including an ohmic resistance $\left(R_{\mathrm{b}}\right)$, two charge-transfer processes $\left(R_{\mathrm{cr}, 1} / C_{\mathrm{d}, 1}\right.$ and $\left.R_{\mathrm{cr}, 2} / C_{\mathrm{d}, 2}\right)$ for the cell reactions, and the Warburg impedance $\left(Z_{\mathrm{w}}\right)$. Since the FG reacted first in the cathode, we assigned $R_{\mathrm{cr}, 1}$ as the reaction resistance of FG. This reflects the contact resistance combined with conductive particles, product shell resistance, and charge-transfer resistance. In this way, $R_{\mathrm{cr}, 2}$ is the reaction resistance of sulfur in this model. The impedance responses were fitted well with this equivalent circuit using the Zview program. We found that the reaction resistance of $\mathrm{FG}\left(R_{\mathrm{cr}, 1}\right)$ was dominant and much higher than that of $R_{\mathrm{cr}, 2}$ for both FG/S-1 and FG/S-2. In addition, FG/S-2 showed a lower resistance for both reactions of FG and sulfur $\left(R_{\mathrm{cr}, 1}=26.1 \pm 1.70 \Omega \mathrm{cm}^{-2}, R_{\mathrm{cr}, 2}=8.6 \pm 1.96 \Omega \mathrm{cm}^{-2}\right)$ than FG/ $\mathrm{S}-1\left(R_{\mathrm{cr}, 1}=36.5 \pm 3.74 \Omega \mathrm{cm}^{-2}, R_{\mathrm{cr}, 2}=15.2 \pm 4.13 \Omega \mathrm{cm}^{-2}\right)$. These results confirm the impressive synergistic effects for FG/ S-2 with the presence of monoclinic sulfur after the meltdiffusion treatment. Furthermore, due to the charge transfer between FG and sulfur, a different sulfur reduction reaction route would occur with faster kinetics, resulting in higher discharge voltage and better rate capability. Although the formation of stable monoclinic sulfur and its specific mechanism behind improving the discharge performance of the cell is not quite clear, the present study has successfully demonstrated the remarkable performance enhancement of batteries using
FG/S hybrid cathodes. Optimization of the cathode components and further advances in the method of sulfur incorporating would contribute to the development of practical high energy and high power density lithium primary cells.

\section{Conclusion}

A simple and effective strategy was proposed and evaluated for developing high-performance $\mathrm{Li} / \mathrm{CF}_{x}$ batteries. A novel hybrid cathode of fluorinated graphene incorporating sulfur was successfully prepared for the first time and extraordinary discharge behavior was observed. Electrochemical tests showed that the hybrid cathodes result in enhanced discharge performance, including increased specific capacity, higher discharge voltage, and better rate capability. In particular, the FG/S-2 cathode with monoclinic sulfur show the highest energy density of $2341 \mathrm{~W} \mathrm{~h} \mathrm{~kg} \mathrm{k}^{-1}$ and a maximum power density of $13621 \mathrm{~W} \mathrm{~kg}^{-1}$ at a current rate of $8.0 \mathrm{~A} \mathrm{~g}^{-1}$. These impressive results benefitted from the high specific capacity of sulfur, while the hybridized cathode had faster ion transport, especially over the main discharge range. Furthermore, a synergistic effect and effective charge transfer in this novel hybrid system have been demonstrated with the use of melt-diffusion method, suggesting that the presence of monoclinic sulfur could impart significant improvements in the energy and power density output.

\section{Conflicts of interest}

There are no conflicts to declare.

\section{Acknowledgements}

This work was supported by grants from the Program of Graphene Special Innovative Fund of AECC Beijing Institute of Aeronautical Materials.

\section{Notes and references}

1 Y. Dai, S. Cai, L. Wu, W. Yang, J. Xie, W. Wen, J.-C. Zheng and Y. Zhu, J. Mater. Chem. A, 2014, 2, 20896-20901.

2 Y. Ma, H. Zhang, B. Wu, M. Wang, X. Li and H. Zhang, Sci. Rep., 2015, 5, 14949.

3 Q. Zhang, K. J. Takeuchi, E. S. Takeuchi and A. C. Marschilok, Phys. Chem. Chem. Phys., 2015, 17, 22504-22518.

4 Y. Li and W. Feng, J. Power Sources, 2015, 274, 1292-1299.

5 Y. Zhu, L. Zhang, H. Zhao and Y. Fu, J. Mater. Chem. A, 2017, 5, 796-803.

6 S. S. Zhang, D. Foster, J. Wolfenstine and J. Read, J. Power Sources, 2009, 187, 233-237.

7 T. Nakajima, R. Hagiwara, K. Moriya and N. Watanabe, J. Electrochem. Soc., 1986, 133, 1761-1766.

8 T. Nakajima, A. Mabuchi, R. Hagiwara, N. Watanabe and F. Nakamura, J. Electrochem. Soc., 1988, 135, 273-277.

9 P. Lam and R. Yazami, J. Power Sources, 2006, 153, 354-359. 
10 R. Yazami, A. Hamwi, K. Guérin, Y. Ozawa, M. Dubois, J. Giraudet and F. Masin, Electrochem. Commun., 2007, 9, 1850-1855.

11 Q. Zhang, S. D'Astorg, P. Xiao, X. Zhang and L. Lu, J. Power Sources, 2010, 195, 2914-2917.

12 H. Groult, C. M. Julien, A. Bahloul, S. Leclerc, E. Briot and A. Mauger, Electrochem. Commun., 2011, 13, 1074-1076.

13 L. Zhu, L. Li, J. Zhou, Y. Pan, W. Lei and Z. Ma, Int. J. Electrochem. Sci., 2016, 11, 6413-6422.

14 A. Kozawa, J. Electrochem. Soc., 1987, 134, 780-782.

15 M. Nagata, J. Yi, M. Tomcsi and H. Tsukamoto, ECS Trans., 2011, 33, 223-237.

16 P. Meduri, H. Chen, X. Chen, J. Xiao, M. E. Gross, T. J. Carlson, J.-G. Zhang and Z. D. Deng, Electrochem. Commun., 2011, 13, 1344-1348.

17 H. Gan, R. S. Rubino and E. S. Takeuchi, J. Power Sources, 2005, 146, 101-106.

18 K. Chen, D. R. Merritt, W. G. Howard, C. L. Schmidt and P. M. Skarstad, J. Power Sources, 2006, 162, 837-840.

19 Z. Liu, J. Li, J. Xiang, S. Cheng, H. Wu, N. Zhang, L. Yuan, W. Zhang, J. Xie, Y. Huang and H. Chang, Phys. Chem. Chem. Phys., 2017, 19, 2567-2573.

20 S. Xin, L. Gu, N.-H. Zhao, Y.-X. Yin, L.-J. Zhou, Y.-G. Guo and L.-J. Wan, J. Am. Chem. Soc., 2012, 134, 18510-18513.

21 Y. Wang, W. C. Lee, K. K. Manga, P. K. Ang, J. Lu, Y. P. Liu, C. T. Lim and K. P. Loh, Adv. Mater., 2012, 24, 4285-4290.

22 C. Sun, Y. Feng, Y. Li, C. Qin, Q. Zhang and W. Feng, Nanoscale, 2014, 6, 2634-2641.
23 L. Zhan, S. Yang, Y. Wang, Y. Wang, L. Ling and X. Feng, Adv. Mater. Interfaces, 2014, 1, 1300149.

24 L. K. Templeton, D. H. Templeton and A. Zalkin, Inorg. Chem., 1976, 15, 1999-2001.

25 S. Moon, Y. H. Jung, W. K. Jung, D. S. Jung, J. W. Choi and D. K. Kim, Adv. Mater., 2013, 25, 6547-6553.

26 S. C. Jung and Y.-K. Han, J. Power Sources, 2016, 325, 495500.

27 U. Gelius, P. F. Hedén, J. Hedman, B. J. Lindberg, R. Manne, R. Nordberg, C. Nordling and K. Siegbahn, Phys. Scr., 1970, 2, 70 .

28 U. Gelius, B. Roos and P. Siegbahn, Chem. Phys. Lett., 1970, 4, 471-475.

29 L. Zhang, L. Ji, P.-A. Glans, Y. Zhang, J. Zhu and J. Guo, Phys. Chem. Chem. Phys., 2012, 14, 13670-13675.

30 M.-S. Park, J.-S. Yu, K. J. Kim, G. Jeong, J.-H. Kim, Y.-N. Jo, U. Hwang, S. Kang, T. Woo and Y.-J. Kim, Phys. Chem. Chem. Phys., 2012, 14, 6796-6804.

31 K. Balakumar and N. Kalaiselvi, RSC Adv., 2015, 5, 3400834018.

32 R. A. Walton, Coord. Chem. Rev., 1980, 31, 183-220.

33 T. Jaumann, J. Balach, M. Klose, S. Oswald, J. Eckert and L. Giebeler, J. Electrochem. Soc., 2016, 163, A557-A564.

34 P. J. Sideris, R. Yew, I. Nieves, K. Chen, G. Jain, C. L. Schmidt and S. G. Greenbaum, J. Power Sources, 2014, 254, 293-297.

35 W. Weppner and R. A. Huggins, J. Electrochem. Soc., 1977, 124, 1569-1578. 